\title{
Between central control and local responsiveness: striking the balance
}

\author{
RUDOLF KLEIN
}

Mr Patrick Jenkin, the Secretary of State for Social Services, is the latest in a long line of ministers to try to find a solution to some of the central dilemmas of the NHS. His consultative document, Patients First, ${ }^{1}$ is one more attempt to find an appropriate balance between centralisation and responsiveness to local circumstances, between democracy seen as accountability to Parliament and democracy seen as participation by representatives of citizens in NHS affairs.

To understand the nature of these dilemmas, it is helpful to start with the Cabinet debate in 1945 when Aneurin Bevan first presented his proposals for the creation of the NHS.* When Bevan produced his plan, it was immediately opposed by Herbert Morrison, the Lord President of the Council and a champion of local government. If the new regional and local management boards were to be "subject to the minister's direction on all questions of all policy," Morrison argued, then they would be "mere creatures of the Ministry of Health, with little vitality of their own." Yet, Morrison pointed out, "it is difficult under a State system to envisage the alternative situation in which, in order to give them vitality, they are left free to spend Exchequer money without the minister's approval and to pursue policies which at any rate in detail may not be the minister's, but for which he would presumably be answerable."

Bevan never met Morrison's argument head on: his answer took the form of a counterattack, arguing that handing over health services to local government would not only be inefficient and prevent the achievement of national standards of provision but would also arouse much more opposition than his own plan. "Such an alternative," he wrote, "would rouse a tornado compared with any passing thunderstorm my scheme may provoke." In any case, he rejected Morrison's dilemma: "The danger of concentrating police powers in one minister is obvious, but I am sure that the Lord President will not press this analogy. There can be no Gestapo of hospital orderlies. A centralised service must, indeed, be planned so as to avoid rigidity." But though the new regional and local boards would be "the agents (though not, I hope, in any derogatory sense the creatures) of my Department...yet it is precisely by the selection of the right men and women to serve on these bodies that I hope to be able to give them substantial executive powers, subject to broad financial control, and so prevent rigidity. Admittedly, this is a field in which there is room for development in the technique of government, but the problems that will arise should not be incapable of solution."

In the event, there has not been much "development in the technique of government" in the subsequent 35 years of the NHS's history. The problems that have arisen have proved stubbornly resistant of any solution. For the first 20 or so years of the NHS the dilemma was side-stepped. The Ministry of Health, as it was then, was a "laissez-faire" department ${ }^{2}$ that is, it was content to devolve executive power to the regions and the hospital management committees, with little attempt to * Details of these are available in the Public Records Office and are published here for the first time.

University of Bath, Claverton Down, Bath BA2 7AY

RUDOLF KLEIN, MA, professor of social policy enforce national policies for the development of health services. But in the 'sixties, with the publication of the 1962 Hospital Plan, ${ }^{3}$ central planning began to be emphasised. And the 1974 pattern of reorganisation, which is now being reviewed by $\mathrm{Mr}$ Jenkin, can to a large extent be seen as the logical consequence of this new emphasis. The creation of area health authorities, for example, was arguably a sensible response to the problems of planning presented by the existence of different geographical units for the delivery of health and local authority services when these needed to be co-ordinated. Similarly, AHA members were to be chosen not because they were in any sense representative of their communities or professional constituencies but because of their "general ability and personality": their capacity for managing, planning, and monitoring the services provided. ${ }^{4}$ The representative role was hived off to the newly created community health councils.

\section{Subtle change}

So we come to $\mathrm{Mr}$ Jenkin's proposals in his consultative document for changing the 1974 structure. These have two themes: the simplification of the managerial hierarchy by the elimination of one tier and more emphasis on flexibility designed to achieve responsiveness to local needs. Thus the consultative document describes the existing planning arrangements as "over-complicated and bureaucratic," and looks forward to the introduction of a "simpler planning system." Implicitly, then, Mr Jenkin's proposals mark reaction against the 1974 model of a managerial hierarchy running from the centre to the periphery and suggest increased and subtly different responsibilities for the new district health authorities. "The new authorities," the consultative document argues, "should feel themselves to be more clearly responsible for meeting local needs."

The full logic of such an approach would, of course, be to have directly elected district health authorities, whose members would be answerable to local citizens. But given the fact that the NHS is financed out of general taxation-and that there is, at present, no alternative system of local taxation capable of financing such a huge service-this would mean delegating the power to spend without the responsibility for raising the money. This is a recipe for run-away inflation in expenditure -the pattern in Sweden, where local control over services is largely divorced from national responsibility for funding. Moreover, the evidence of massive apathy in local government elections suggests that the turnout of voters to choose members of district health authorities might well be derisory. So it is hard to blame Mr Jenkin for rejecting such a radical solution. But, having rejected it, he faces the familiar Morrisonian dilemma: how to reconcile his responsibility to Parliament for the NHS, which implies a large degree of central control, with ensuring the "vitality" of the local executive bodies.

One tentative-but controversial-answer given by the consultative document is to abolish community health councils: to reintegrate, on the pre-1974 pattern, the managerial and the representative role. Given the smaller size of the new district health authorities, the document argues, "the need for separate consumer representation ... is less clear." The proposal has already drawn angry fire from the Labour Party. Mr Jenkin's 
predecessor as Secretary of State, Mr David Ennals, has already denounced the idea. It would be a "tragedy," he has argued, if CHCs were to disappear. ${ }^{5}$

\section{CHCs: to abolish or not}

Yet a respectable case remains for abolishing community health councils. This has nothing to do with their cost, which, at $£ 4 \mathrm{~m}$ per year, is trivial in relation to the total NHS budget (though to this sum must be added the costs generated by CHCs in terms of the extra administrative burdens created by their activities). The real question surely is whether, given the proposed creation of district health authorities, there will be an excessive overlap in the functions of the new authorities and the $\mathrm{CHCs}$ - to what extent, in other words, the latter will be made redundant. Even at present there is a certain duplication-for example, the members of both AHAs and CHCs tend to make pastoral visits to hospitals. Given the smaller size of the proposed district health authorities, it is arguable that their members will have more opportunity to keep themselves informed about what is happening at the coalface of service delivery without needing the extra information provided by the CHCs. But, leaving aside such general considerations, $\mathrm{CHCs}$ have some specific functions. These were spelled out in the report of the Royal Commission on the NHS. ${ }^{6}$ They are informing the public, representing public opinion, and monitoring local services. So it is worth exploring in more detail whether these functions could effectively be carried out if CHCs were abolished.

\section{INFORMING THE PUBLIC}

This, as seen by the Royal Commission, is a two-way process. It means not only telling people how to complain but also providing a channel for the public to contribute ideas for the development of services. This is an important task: it would be difficult to dispute the need for a patient's friend to help the public to find their way through the maze of services and complaints procedures, whose complexity is often baffling.? It may be, however, that the same service could be provided by other means. For example, if a quarter of the CHCs' collective budget were to be given to citizens, advice bureaux, these might be able to take on the information responsibility. Citizens, advice bureaux have the advantage of an existing network of accessible offices. The network is incomplete but surely it is better to strengthen one system of bureaux which offer advice and help to the citizen than to compound complexity and bewilderment by creating service-specific offices, of whose existence many citizens may not be aware.

\section{REPRESENTING THE PUBLIC}

Members of CHCs do not represent the public in a strict sense: they are not directly elected and their composition does not mirror that of their local communities. ${ }^{*}$ Their membership tends to be both more middle aged and more middle class than the public at large. Indeed, from the start one of their problems has been that the public is largely ignorant of their existence and that they have found it difficult to assess the extent to which arguments put by special interest groups reflect opinion in the community at large. Hence the case, supported by the Royal Commission, for surveys of local opinion designed to elicit the views of consumers. Such surveys carry obvious dangers: collecting statistics of opinions does not necessarily measure the salience or intensity of the views held about specific issues. Morcover, more advanced methods are needed if the opinions are to be based on realistic assumptions about resource constraints. But, even so, there is no reason why such surveys should not be carried out or financed by the district health authorities. Indeed, a statutory responsibility might well be laid on these authorities to show that they have collected adequate information about local opinion before they submit plans for major changes in services.

But CHCs do have a further, and important, representative function, which springs, paradoxically, from the fact that they are unrepresentative in their membership. The formula for choosing their members is deliberately biased in one respect. It is designed to ensure that there will be spokesmen for the least articulate and least assertive consumers of health carethe mentally ill and handicapped, the elderly, and so on. This is achieved by creating a constituency of local voluntary organisations representing these interests, who nominate a third of the CHC membership. And it may be argued that one of the achievements of CHCs has been precisely to represent the interests of those consumers least capable of representing themselves. To jettison this might well reinforce the imbalance in the NHS (and perhaps among the public at large) between those who favour spending on the curative acute services and those who seek the development of the care and maintenance services. Again, however, it might be possible to devise a solution which does not depend on the survival of CHCs. The constituency of local voluntary organisations might be given the right to nominate some members of the district health authorities, thus ensuring the continued representation of the most vulnerable groups of consumers. This would have the added advantage of providing a pool of potential recruits for the new authorities and making sure that the experience and expertise gained by CHC members is not wasted.

\section{MONITORING LOCAL SERVICES}

One of the troubles of the post-1974 NHS is that everyone is supposed to monitor everyone else. The DHSS monitors the regions; the regions monitor the AHAs; the AHAs monitor the districts. So this would seem to be an example of a role where the CHC would simply duplicate that of the new district health authorities. Against this, it might be argued that the monitoring would be more effective if carried out from two different perspectives: the managerial or top-down perspective and the consumer or bottom-up perspective. But even this begs the question of precisely what is meant by monitoring : an invocatory, vogue word whose frequent use simply disguises its emptiness of meaning. The real problem of the NHS is precisely the lack of accepted and established yardsticks against which to measure performance: the absence, in other words, of a suitable armoury of monitoring. Waiting lists are a notoriously ambiguous indicator; cost returns simply tend to generate a new set of questions since above average costs may indicate either exceptionally high standards or low efficiency. And this problem afflicts everyone in the NHS from the DHSS downwards, which tends to explain why monitoring so often takes the form of pernickety nagging about detail and the collection of data which defy interpretation.

The dilemma of the new district health authorities will therefore be the same as that of the existing AHAs-and indeed of all tiers of management in the NHS-whether or not CHCs survive. This is how to obtain information about the performance of the Service which actually has some meaning in terms of efficiency or as indicator of adequacy measured against some assessment of local needs. Rather than persist with a policy of multiplying the number of monitoring bodies, it might be wiser to experiment with devising more effective instruments for breathing some life into the concept. Several options have been put forward in the past-for example, an independent, national audit bureau ${ }^{10}$ or some kind of inspectorate. ${ }^{10}$ And indeed the consultative document raises, tentatively and somewhat opaquely, the possibility that "responsibility for monitoring the quality and efficiency of the ways in which health services are managed and for advising on the development of concluded on $p 424$ 
general practitioner's responsibility with specialist referral if necessary. This would inevitably bring the GP more directly in contact with current medical practice and should lessen the burden on the hospital services. The latter could then function as acute diagnostic and therapeutic units, leaving most of the management to the GP. Similarly, much of the minor surgery, which grossly overloads surgical waiting lists, could be done by suitably trained and interested GPs. This would be appreciated by the patient and provide professional satisfaction for the family doctor.

There is great scope for altering traditional spheres of practice. It is up to the profession-and GPs in particularto explore the possibilities, using closely monitored pilot schemes. Resources are limited: it is important to deploy them efficiently and ensure that patients receive competent, caring service while doctors achieve professional fulfilment.

1 Statutory Instrument 1979 No 1644. National Health Service, England and Wales: The National Health Service (Vocational Training) Regulations 1979. London: HMSO, 1979.

2 Higgins PM. The GP/hospital interface. $7 R$ Coll Physicians $1979 ; 13$ 132-8.

${ }^{3}$ Forsyth G, Logan RFL. The demand for medical care. London: Oxford University Press, 1960.

4 Torrance N, Lawson JAR, Hogg B, Knox JDE. Acute admissions to medical beds. $\mathcal{F} R$ Coll Gen Pract 1972;22:211-9.

(Accepted 19 December 1979)

\section{Commentary RUDOLF KLEIN-continued}

services at the district level" might, experimentally, be exercised by "an advisory group of experienced NHS officers, who would report to the district health authorities."

\section{Health Service auditors}

This is a proposal which should, surely, be eagerly seized on and welcomed. The model for such an inspectorate (the term tends to raise hackles in the NHS but describes the function accurately) already exists-the Health Advisory Service, born as the Hospital Advisory Service in 1969, which covers services for the mentally ill, the elderly, and children in long-term care. This has established the principle and showed the practicability of using peripatetic teams of health service professionals to examine standards and of deriving criteria of excellence and efficiency from the standards set by professionals themselves as distinct from being imposed from the outside. So why not extend the principle and the practice to cover acute services and, dare I suggest, general practitioner services ? Furthermore, why not extend the membership of teams to include community physicians and economists so as to ensure that standards of existing services are not raised at the expense of denying access to those whose needs have not been recognised?

Setting up such teams of health service auditors would have several advantages. It would provide members of district health authorities with an expert source of information independent of their own officers. This would be a direct incentive to exhibit "vitality" in their managerial function rather than being trapped in the quicksands of often dubiously relevant data or meaningless trivia. Similarly, it would permit the DHSS to carry out its inescapable responsibility for the overall operations of the NHS without getting embroiled in interfering in dayto-day management. And, in the context of such an innovation in the "technique of government," the abolition of community health councils might be seen not as a damaging piece of cheeseparing but as part of a fundamental rethink of the problems of running the NHS.

\section{References}

${ }^{1}$ Department of Health and Social Security. Patients First. London: HMSO, 1979.

2 Griffith JAG. Central departments and local authorities. London: Allen and Unwin, 1966.

${ }^{3}$ Ministry of Health. A hospital plan for England and Wales, Cmnd 1604. London: HMSO, 1962.

${ }^{4}$ Secretary of State for Health and Social Services. National Health Service reorganisation: England, Cmnd 5055. London: HMSO, 1972.

5 Hansard, House of Commons, 19 December 1979, col 687.

${ }^{6}$ Royal Commission on the National Health Service. Report, Cmnd 7615. London: HMSO, 1979.

7 Klein R. Complaints against doctors. London: Charles Knight, 1973.

${ }^{8} \mathrm{~K}$ lein $\mathrm{R}$, Lewis J. The politics of consumer representation. London: Centre for Studies in Social Policy, 1976.

${ }^{9}$ Bochel D, Maclaren M. Representing the interests of the public? The case of the Local Health Councils in Scotland. Fournal of Social Policy $1979 ; 8: 449-73$.

${ }^{10}$ Klein R, Hall P. Caring for quality in the caring services. London: Centre for Studies in Social Policy, 1974.

\section{When industrial relations break down NORMAN ELLIS-continued}

local management was faced with ever-changing and often conflicting advice from the DHSS; local discretion was granted and subsequently withheld with increasing rapidity.

I interpret the new DHSS guidelines as a public declaration that this era of ministerial intervention is now formally closed. The "hot line" between the minister and the unions at national level has been withdrawn. Both management and unions are on their own and they may presume that after this circular they can expect little in the way of sustenance or sympathy from the DHSS. I presume that the meaning of this public declaration is that the abstentionist policy will now have to be adhered to by the Government until a subsequent and equally public decision is taken to change it.

Having been castigated for its lack of confidence in the past and its failure to apply coherent and consistent policies during previous disputes, NHS management is now encouraged by the Government to demonstrate a newly found virility. Some more seasoned observers might suggest that this document overreacts: regrettably the same lack of experience and confidence in coping with a sustained trade union challenge at the work place can leave management with either the appearance of inactivity and ineptitude or a false sense of purpose where weak intentions are disguised by tough words. They are commonly two sides of the same coin.

\section{References}

${ }^{1}$ Department of Health and Social Security. If industrial relations break down (HC(79)20). London:DHSS, 1979.

2 The Volunteer Centre. Guidelines for relationships between volunteers and paid non-professional workers. Berkhamsted: The Volunteer Centre, 1979.

3 Dyson R. Industrial action 1979: What can we learn? Br Med f 1979 ; : 1435-7. 